\author{
Luz Elena Figueroa Gómez \\ Universidad Icesi, Colombia \\ luz.figueroa@correo.icesi.edu.co \\ Paula Andrea Cerón Arboleda \\ Universidad Icesi, Colombia \\ paula.ceron@correo.icesi.edu.co
}

\title{
La eficacia de las acciones populares y sus indicadores
}

\begin{abstract}
This article presents a discussion of some of the results of a research study regarding the effectiveness of popular actions in the city of Cali between 1998 and 2008. It also provides a brief description of the concept of effectiveness from the perspective of constitutional doctrine and jurisprudence, and discusses the authors' individual research findings.
\end{abstract}

Key words: Political constitution, popular actions, efficiency, law.

\section{Introducción}

En 1991 la Asamblea Nacional Constituyente consideró la necesidad de incluir en la Nueva Constitución las acciones populares. Éstas se encontraban consagradas de manera dispersa en nuestra legislación, ${ }^{1}$ pero no eran suficientes para atender nuevas realidades que hicieron evidente el hecho de que se podían afectar los intereses de una "pluralidad más o menos extensa de individuos". ${ }^{2}$ Por lo anterior, se presentaron varios proyectos que buscaban garantizar la defensa de los derechos colectivos.

Concretamente se presentaron tres proyectos. El primero, propuesto por el Gobierno, buscaba insertar estas acciones dentro del concepto de derecho de petición, ya que de esta forma se garantizaría el cumplimiento de los derechos colectivos con el recurso de amparo de protección individual, por ser el derecho de petición un derecho fundamental. Sin embargo, esta propuesta no tuvo mucha

1 Código Civil, Ley 9 de 1989 y Decreto 2303 de 1989.

2 Corte Constitucional. Sentencias C-215 de 1999. C-569 de 2004. M.P: Rodrigo Uprimny Yepes.

C-377 de 2002 M.P: Clara Inés Vargas Hernández. 
acogida pues se podría entender que se trataba de actuaciones administrativas, que necesitarían obligatoriamente el agotamiento de la vía gubernativa, lo que de antemano contradice claramente el espíritu de esta acción. El segundo proyecto fue presentado por la Alianza Democrática M-19. En esta propuesta dichas acciones tenían la denominación de Acción pública de defensa y se limitaba a obtener reparaciones colectivas, sin tener en cuenta la finalidad preventiva del daño colectivo. En términos del M-19 se buscaba:

[...] demandar de manera individual o colectiva, en acción pública de defensa, a cualquier persona o entidad, pública o privada, por conductas o actividades que lesionen a una comunidad en particular o a la sociedad en su conjunto y obtener para éstas el resarcimiento correspondiente. La ley que reglamenta dicha acción podrá establecer para el actor algún tipo de recompensa o retribución en el evento de que se logre el restablecimiento del derecho colectivo (Gaceta Constitucional, 1991, No. 22 p. 261).

La tercera propuesta la presentó el constituyente Jesús González Rubio quien manifestó, en concordancia con las demás propuestas, que este tipo de acciones debían estar relacionadas en todo su sentido con la justicia y propuso como elemento novedoso que éstas debían elevarse a un rango constitucional para darles mayor efectividad. Igualmente manifestó que en esta Ley debía estar incluida la indemnización del daño y además propuso que se les permitiera a los ciudadanos emplear esta acción cuando los productos, bienes y servicios que adquirieran adolecieran de la calidad o de la cantidad estipulada.

Finalmente, la Asamblea aprobó el Artículo 88 de la Constitución, en el que se unificaron las propuestas, quedando las acciones populares como un reflejo de dos de los principios en los que se funda el Estado social de derecho en Colombia: dignidad humana y solidaridad. ${ }^{3}$

Posteriormente, la Ley 472 de 1998 desarrolló el Artículo 88 de la Constitución, ${ }^{4}$ haciendo explícito en su exposición de motivos el desconocimiento de los ciudadanos de las acciones populares hasta entonces vigentes. Así, éstas son reguladas y se consagran una serie de principios constitucionales que permiten a los ciudadanos acceder con facilidad al sistema judicial a fin de que se tomen rápidamente las medidas necesarias para proteger sus derechos colectivos amenazados o vulnerados. Estos principios, que inicialmente la

3 Corte Constitucional. Sentencia C-569 de 2004.

4 Artículo 88: "La ley regulará las acciones populares para la protección de los derechos e intereses colectivos, relacionados con el patrimonio, el espacio, la seguridad y la salubridad públicas, la moral administrativa, el ambiente, la libre competencia económica y otros de similar naturaleza que se definen en ella [...] También regulará las acciones originadas en los daños ocasionados a un número plural de personas, sin perjuicio de las correspondientes acciones particulares". 
Constitución consagra para regir la función administrativa, ${ }^{5}$ también son de aplicación para la administración de justicia, según la Corte Constitucional (Sáchica de Moncaleano, 1999).

Uno de los principios que rige el trámite de las acciones populares es el de la eficacia, consagrado en el Artículo 209 de la Constitución, de manera general para la función administrativa y toda actividad judicial y de manera concreta en el Artículo 5 de la Ley 472 de $1998 .{ }^{6}$ De esta forma, se estima que la eficacia de las acciones populares para la protección de los derechos colectivos debe abordarse desde una perspectiva procesal, ya que ésta permite la vigencia o materialización del derecho sustancial, en la medida en que se verifiquen sus indicadores.

Dichos indicadores se orientan en primer lugar al sujeto que interpone la acción, en nombre de la comunidad cuyo derecho ha sido vulnerado o amenazado; en segundo lugar al agente vulnerador del derecho; en tercer lugar al cumplimiento de los principios que rigen el trámite procesal; y, finalmente, a otras instituciones que en el trámite del proceso pueden permitir la protección de los derechos colectivos.

En esta vía, este documento expone algunos resultados de una investigación realizada durante al año 2009 sobre la eficacia de las acciones populares en la ciudad de Cali, que tuvo como centro el análisis de las acciones tramitadas en el Tribunal Contencioso Administrativo del Valle y en los juzgados administrativos de Cali, entre los años 1998 y 2008.

A continuación describiremos brevemente, desde la doctrina y la jurisprudencia constitucional, el concepto de eficacia. Posteriormente expondremos los hallazgos de la investigación en lo que respecta a cada uno de los indicadores y, para finalizar, presentaremos un conjunto de conclusiones que se establecen a partir del trabajo realizado.

\section{El concepto de eficacia}

La eficacia, en términos generales, hace referencia a la capacidad para lograr los fines propuestos. En el ámbito jurídico la noción de eficacia guarda una relación estrecha con la escuela realista del derecho, ya que implica la materialización de ciertos bienes y el logro de unos fines que resultan valiosos en una sociedad, a través de la aplicación de contenidos normativos válidos, por parte

5 Artículo 209 de la Constitución Política: "La función administrativa está al servicio de los intereses generales y se desarrolla con fundamento en los principios de igualdad, moralidad, eficacia, economía, celeridad, imparcialidad y publicidad, mediante la descentralización, la delegación y la desconcentración de funciones".

6 Artículo 5 Ley 472 de 1998: "TRÁMITE. El trámite de las acciones reguladas en esta ley se desarrollará con fundamento en los principios constitucionales y especialmente en los de prevalencia del derecho sustancial, publicidad, economía, celeridad y eficacia". 
de un juez, en una situación concreta. En un Estado social de derecho, como el de Colombia, no sólo se amplía el catálogo de los derechos humanos como bienes valiosos de la sociedad, sino que se procura su materialización y vigencia mediante la consagración de mecanismos judiciales idóneos de protección, que operen frente a posibles amenazas o vulneración.

La eficacia constituye en el país uno de los principios que rige la actividad judicial, y de manera concreta el ejercicio de tales acciones. A continuación presentaremos el modo en que tanto la doctrina como los pronunciamientos de la Corte Constitucional, interpretan el concepto de eficacia.

\section{La eficacia según la doctrina}

El concepto de eficacia ha sido abordado por la doctrina como un problema de aplicación del derecho. Para Bobbio (1994), la norma jurídica comprende tres criterios de valoración: la eficacia, la validez y la justicia. En concreto, para este autor, el criterio de eficacia puede plantearse desde dos perspectivas: la primera sugiere que se presenta eficacia cuando la norma se cumple por las personas que están obligadas a hacerlo y la segunda establece que hay eficacia cuando, en caso de transgresión de la norma, existen medios coercitivos para imponerla.

Asimismo, Bobbio (1994) establece cuatro grados de eficacia en el cumplimiento de normas: el primer grado se produce cuando la norma se cumple de manera espontánea; el segundo, cuando se cumple sólo mediante la coacción; el tercero ocurre cuando la norma no se cumple a pesar de aplicar medidas de coacción; y el cuarto, el grado de mayor ineficacia, sucede cuando, a pesar del incumplimiento de la norma no se aplican medidas de coacción. Advierte este autor que todo estudio sobre la eficacia de una norma implica pensar el problema de la aplicación de las normas jurídicas, el cual recae en el comportamiento de un determinado grupo social. Es por ello que denomina al problema de la eficacia como un problema fenomenológico del derecho (Betegón. et. al, 1997), esto es, un asunto que compete a la sociología jurídica.

Si bien Betegón, et. al, (1997) y Bobbio (1994) coinciden en concebir el problema de la eficacia como un asunto de orden fenomenológico, ambos ubican su estudio en campos disímiles. Por un lado, Bobbio afirma que el estudio de la eficacia, pensado como un aspecto particular de la norma, debe producirse en la sociología jurídica, mientras que, por otro, Betegón et. al. (1997) ubican su análisis en el campo de la política jurídica, en tanto consideran necesario examinar si el diseño de las instituciones es idóneo para garantizar los fines que se proponen con determinada norma.

Asumiendo ambas perspectivas, tendríamos que concluir que un análisis de la eficacia de las acciones populares exige centrarse tanto en las personas obligadas a cumplir las normas como en los medios e instituciones que existen para que éstas se cumplan de manera coercitiva. 


\section{La eficacia según la Corte Constitucional.}

La Corte Constitucional determina la eficacia como principio consagrado en el Artículo 2 de la Constitución, a través del cual el Estado debe garantizar la vigencia de los principios, deberes y derechos consagrados en la misma. ${ }^{7}$ Igualmente la Corte en Sentencia T-406 de 1992, definió que los principios constitucionales

[...] consagran prescripciones jurídicas generales que suponen una delimitación política y axiológica reconocida [...] lo cual hace de ellos normas de aplicación inmediata, tanto por el legislador como por el juez constitucional $[\ldots]$ jamás pueden ser desconocidos $[\ldots]$ son normas que establecen un deber ser específico [...].

En este sentido, se concibe a la eficacia como principio constitucional y norma jurídica, imperativa, de aplicación inmediata en el campo procedimental, que garantiza la vigencia de los derechos constitucionales de manera real y oportuna. ${ }^{8}$ Ello indica que la eficacia está relacionada con el derecho fundamental de acceso a la justicia, ${ }^{9}$ por lo que limitar este derecho constituye un atentado contra la eficacia de los mecanismos protectores. ${ }^{10}$ Para evitar esta situación se requiere de jueces activos, con poderes para actuar de manera oficiosa, que decidan tras estudio riguroso si hubo violación o amenaza a determinado derecho.

Para la Corte Constitucional las acciones populares son el reflejo de nuestro Estado social y democrático de derecho, ya que, como decíamos, se fundan en el respeto por la dignidad humana y la solidaridad. Es en virtud de la solidaridad que la participación de la comunidad en la defensa de los derechos colectivos es esencial, razón por la cual debe garantizarse plenamente el ejercicio de las acciones populares. Por lo anterior, la restricción a la comunidad para ejercer la acción se traduce en una restricción del acceso a la justicia y en reducción del grado de eficacia del mecanismo. En materia de derechos colectivos, la participación de la comunidad "optimiza los mecanismos de defensa de las personas frente a los poderes del estado y a los de grupos económicamente fuertes". ${ }^{11}$

El acceso a la justicia también se verifica en la mayor exigibilidad de los mecanismos procedimentales para la protección de los derechos de rango

7 Constitución Política, Artículo 2: "Son fines esenciales del Estado: servir a la comunidad, promover la prosperidad general y garantizar la efectividad de los principios, derechos y deberes consagrados en la Constitución [...]".

8 Corte Constitucional. A 186 del 2006. M.P: Humberto Antonio Sierra Porto.

9 Artículo 229: "Se garantiza el derecho de toda persona para acceder a la administración de justicia $[\ldots] "$.

10 Corte Constitucional. C-569 del 2004. M.P: Rodrigo Uprimny Yepes.

11 Corte Constitucional. C-569 del 2004, C-215 de 1999 y C-1062 del 2000. 
constitucional. Según la Corte, las instancias, las vías y en general el esquema legal, que se derivan de los mecanismos de amparo de derechos constitucionales, deben obedecer al "diseño constitucional orientado por el principio de solidaridad, el derecho de acceder a la justicia y los modelos definitorios del Estado constitucional". ${ }^{12}$ En este sentido, la ley se convierte en un instrumento para garantizar la efectividad de los derechos, en particular si ésta se adecúa a la realidad, tal y como lo ha manifestado repetidamente la Corte. ${ }^{13}$

La Corte Constitucional también ha vinculado la eficacia con la prontitud con la que el juez de instancia falla una medida de protección. La Corte afirma que ésta es una garantía del derecho de acceder a la justicia. El propósito entonces de la actividad jurisdiccional, al actuar de manera pronta e inmediata, es "lograr la efectividad de los derechos, obligaciones, garantías y libertades públicas". ${ }^{14}$ En este sentido, y de acuerdo con la Corte, en materia procedimental la eficacia guarda relación directa con la debida notificación de las actuaciones, el principio de la doble instancia y, concretamente en las acciones populares, con el principio de celeridad, al consagrarse como únicos recursos los de reposición y apelación.

Por otro lado, la Corte ha expuesto que el concepto de eficacia no es uniforme, pues puede presentarse en dos sentidos. En primer lugar, en un sentido amplio, cuando la norma determina una conducta que no necesariamente implica el logro de sus objetivos. Por el contrario, en sentido estricto, cuando una norma, además de lograr la realización de la conducta que ha previsto, consigue también los objetivos planteados. Asimismo, la eficacia se da cuando los objetivos se obtienen "a través de la utilización de los mejores medios posibles". ${ }^{15}$

Por lo anterior, según la Corte Constitucional, para determinar si las acciones populares, consagradas en la Ley 472 de 1998, son eficaces en la protección de los derechos colectivos, debe analizarse por lo menos los siguientes seis aspectos: 300 1) Si los jueces han resuelto o no el caso concreto con sentencia de fondo. 2) Si se cumplió o no con el principio de celeridad. 3) Si se aplicó o no el principio del juez pro actione, que no es otra cosa que la impulsión oficiosa que le da el juez a la acción, ya sea para determinar la veracidad de los hechos o para evitar que se concrete la amenaza a un derecho colectivo. 4) Si existió o no equidad entre las partes. 5) Si hubo o no prevalencia del derecho sustancial en el trámite de la acción y 6) Si se acudió o no al precedente judicial.

12 Corte Constitucional. C-569 del 2004, C-215 de 1999 y C-1062 del 2000.

13 Corte Constitucional. Sentencia C-542 de 1993. M.P: Jorge Arango Mejía.

14 Corte Constitucional. C-580 del 2002. M.P: Rodrigo Escobar Gil. Sentencia C-365 del 2000. M.P: Vladimiro Naranjo Mesa. Sentencia T-378 de 1994. M.P: Eduardo Cifuentes Muñoz. Sentencia T-222 de 1992. M.P: Ciro Angarita Barón.

15 Corte Constitucional. Sentencia C-546 de 1992. M.P: Ciro Angarita Barón y Alejandro Martínez Caballero. 


\section{Análisis de indicadores de eficacia en las acciones populares}

Como decíamos previamente, un análisis de los indicadores de eficacia en las acciones populares hace referencia al sujeto accionante, al acatamiento de los fallos por parte de los agentes que vulneran o amenazan los derechos, al cumplimiento de los principios procesales en el trámite de las acciones y, de una manera transversal, al cumplimiento del precedente judicial. Analizaremos a continuación cada uno de estos indicadores.

Sujeto accionante: respecto del sujeto actor, la eficacia supone un directo y fácil acceso por parte de cualquier ciudadano a los estrados judiciales. Siendo la acción popular una acción pública constitucional, que se funda en el principio de la solidaridad, ${ }^{16}$ el Estado debe facilitar la posibilidad de que cualquier ciudadano, sin mediación de un abogado, represente los intereses de la comunidad afectada, lo que implica minimizar los formalismos procesales. La Ley 472 de 1998 en su Artículo 13, prevé el hecho de que, si el accionante no actúa a través de un abogado, ${ }^{17}$ la Defensoría del Pueblo sea notificada de la iniciación de esta acción, para que pueda asistir o intervenir si lo considera necesario.

La calidad de accionante también se relaciona con el hecho de que éste sea persona natural o jurídica. Es importante verificar esta condición, ya que si el accionante es una persona jurídica podrá tener, por ejemplo, mayor capacidad económica para asumir un proceso judicial.

Igualmente es importante establecer si se trata de una persona jurídica de derecho público, ya que de manera expresa el legislador, en la Ley 472 de 1998 en su Artículo 12, ${ }^{18}$ ha determinado que las entidades públicas, con funciones de control y vigilancia, y los alcaldes y demás funcionarios públicos, que tengan entre sus funciones promover y proteger los derechos, están legitimados para

16 Corte Constitucional. Sentencias C-459 de 2004. M.P: Jaime Araújo Rentería y C-215 de 1999. Ídem, en esta oportunidad la Corte citó textualmente los debates que se dieron en la Asamblea Nacional Constituyente, con referencia a la acción popular, en el Proyecto de Acto Reformatorio No. 23, cuyo delegatario fue Álvaro Gómez Hurtado: “... se justifica que se dote a los particulares de una acción pública que sirva de instrumento para poner en movimiento al Estado en su misión, bien de dirimir los conflictos que pudieren presentarse, bien de evitar los perjuicios que el patrimonio común pueda sufrir".

17 Artículo 13. Ejercicio de la accion popular. Los legitimados para ejercer acciones populares pueden hacerlo por sí mismos o por quien actúe en su nombre. Cuando se interponga una acción popular sin la intermediación de un apoderado judicial, la Defensoría del Pueblo podrá intervenir, para lo cual, el juez deberá notificarle el auto admisorio de la demanda.

18 Artículo 12. Titulares de las acciones. Podrán ejercitar las acciones populares: A) Las entidades públicas que cumplan funciones de control, intervención o vigilancia, siempre que la amenaza o vulneración a los derechos e intereses colectivos no se haya originado en su acción u omisión. B) El Procurador General de la Nación, el Defensor del Pueblo y los Personeros Distritales y municipales, en lo relacionado con su competencia. C) Los alcaldes y demás servidores públicos que por razón de sus funciones deban promover la protección y defensa de estos derechos e intereses. 
presentar una acción popular. En este sentido puede presentarse una contradicción, porque en ciertos casos los sujetos legitimados para interponer una acción popular pueden ser los mismos que amenazan o vulneran un derecho colectivo.

Acatamiento del fallo. En asuntos conocidos por los jueces administrativos, la eficacia se relaciona con el hecho de que quien amenaza o vulnera un derecho colectivo acate y cumpla el fallo que ordena cesar dicha amenaza o vulneración. Sobre este aspecto, puede decirse que existen dos mecanismos en la Ley 472 de 1998, que permiten al juez verificar si la sentencia que amparó un derecho colectivo fue o no eficaz. El primero es que el juez, luego de terminado el proceso, conserve la competencia a fin de que pueda tomar las medidas necesarias para la ejecución de la misma, ${ }^{19}$ y el segundo es la figura procesal denominada incidente de desacato, ${ }^{20}$ por medio del cual se sanciona con multa a la persona que incumpla la orden judicial de cesar la vulneración o amenaza a los derechos colectivos. A través de un auto de cumplimiento, tanto el operador jurídico como el actor popular pueden verificar el acatamiento de la sentencia y el cumplimiento de las medidas de protección ordenadas al agente vulnerador.

Cumplimiento de los principios procesales. Finalmente, sobre este aspecto, la eficacia, en el marco de la actividad jurisdiccional, no sólo actúa como principio en sí mismo, sino que también se articula con otros principios de tipo procesal, tales como:

a) Celeridad: este principio se consagra en el Artículo 209 de la Constitución y en los Artículos 5 y 6 de la Ley 472 de 1998. ${ }^{21}$ Como se explicó antes, este principio permite dar mayor agilidad al proceso, razón por la cual guarda relación

19 Artículo 34. Sentencia. En la sentencia el juez señalará un plazo prudencial, de acuerdo con el alcance de sus determinaciones, dentro del cual deberá iniciarse el cumplimiento de la providencia y posteriormente culminar su ejecución. En dicho término el juez conservará la competencia para tomar las medidas necesarias para la ejecución de la sentencia de conformidad con las normas contenidas en el Código de Procedimiento Civil y podrá conformar un comité para la verificación del cumplimiento de la sentencia en el cual participarán además del juez, las partes, la entidad pública encargada de velar por el derecho o interés colectivo, el Ministerio Público y una organización no gubernamental con actividades en el objeto del fallo. También comunicará a las entidades o autoridades administrativas para que, en lo que sea de su competencia, colaboren en orden a obtener el cumplimiento del fallo.

20 Artículo 41. Desacato. La persona que incumpliere una orden judicial proferida por la autoridad competente en los procesos que se adelanten por acciones populares, incurrirá en multa hasta de cincuenta (50) salarios mínimos mensuales con destino al Fondo para la Defensa de los Derechos e Intereses Colectivos, conmutables en arresto hasta de seis (6) meses, sin perjuicio de las sanciones penales a que hubiere lugar. La sanción será impuesta por la misma autoridad que profirió la orden judicial, mediante trámite incidental y será consultada al superior jerárquico, quien decidirá en el término de tres (3) días si debe revocarse o no la sanción. La consulta se hará en efecto devolutivo. 21 Artículo 5o. Trámite. El trámite de las acciones reguladas en esta ley se desarrollará con fundamento en los principios constitucionales y especialmente en los de prevalencia del derecho sustancial, publicidad, economía, celeridad y eficacia [...]. Artículo 6o. Trámite preferencial. Las 
con el trámite preferencial de la acción. Esto significa que el juez de instancia deberá darle prelación frente a otras acciones que se tramitan en su despacho, a excepción del hábeas corpus, la acción de tutela y la acción de cumplimiento. Siendo la acción popular una acción constitucional, los términos para su trámite son de estricto cumplimiento. Haciendo una revisión de los términos, establecidos por la Ley 472 de 1998 para su trámite, se tiene que éste oscila entre los seis meses y un año.

b) Doble instancia: para controvertir la sentencia en la acción popular, la Ley 472 consagró en los Artículo 36 y 37 los recursos de reposición y apelación. ${ }^{22}$ Éstos se relacionan con el principio de celeridad pues, como lo afirman la Corte Constitucional y el Consejo de Estado, en materia de acciones populares no es necesario consagrar más recursos que los que la ley ya determinó, por tratarse de un mecanismo rápido que no merece dilaciones. ${ }^{23}$

Debe tenerse en cuenta que la entrada en funcionamiento de los juzgados administrativos, en el año 2006, permitió que los sujetos procesales continuaran manteniendo un contacto directo con las actuaciones judiciales que debían surtirse en la segunda instancia, ya que son estos Tribunales los que conocen de los recursos, y no el Consejo de Estado. Asimismo, la medida favoreció la descongestión de la labor del Consejo de Estado y de los Tribunales Contenciosos. Es importante anotar, por último, que el funcionamiento de los juzgados administrativos, desde el año 2006 hasta el 2009, trajo como consecuencia la inexistencia de un órgano de cierre de las acciones en la segunda instancia, ocasionando un desconocimiento de la opinión pública de los casos de vulneración o amenaza de derechos colectivos y de la aplicación y unificación del precedente judicial. Por lo anterior, puede decirse que la Ley 1285 de 2009, que reformó oportunamente la ley estatutaria de la administración de justicia, le otorgó al Consejo de Estado, como tribunal supremo de lo contencioso administrativo, la función de hacer una revisión eventual de las sentencias o providencias que determinen la finalización o archivo tanto de las acciones populares como de las de grupo.

c) Equilibrio entre las partes: tanto en los debates de la Asamblea Nacional Constituyente, como en la exposición de motivos que se presentó para aprobar la ley 472 de 1998 se planteó la necesidad de tener en cuenta el hecho de que

acciones populares preventivas se tramitarán con preferencia a las demás que conozca el juez competente, excepto el recurso de Habeas Corpus, la Acción de Tutela y la Acción de cumplimiento. 22 Artículo 36. Recurso de reposicion. Contra los autos dictados durante el trámite de la Acción Popular procede el recurso de reposición, el cual será interpuesto en los términos del Código de Procedimiento Civil. Artículo 37. Recurso de apelacion. El recurso de apelación procederá contra la sentencia que se dicte en primera instancia, en la forma y oportunidad señalada en el Código de Procedimiento Civil, y deberá ser resuelto dentro de los veinte (20) días siguientes contados a partir de la radicación del expediente en la Secretaría del Tribunal competente.

23 Corte Constitucional. C-377 de 2002. 
en los asuntos referentes a la protección de derechos colectivos generalmente se involucran como accionados entidades públicas o particulares que ostentan frente al ciudadano una posición de poder dominante. La Corte Constitucional manifestó al respecto que "las acciones populares parten del hecho de que quienes las promueven se encuentran en una situación de desigualdad". ${ }^{24}$ Es por ello que la acción popular se rige por el principio del equilibrio entre las partes y el juez administrativo está obligado a tomar las medidas que considere necesarias para mantenerlo.

En un análisis sobre la eficacia fundado en este aspecto, debe tratarse, por ejemplo, de identificar al sujeto que asumió los gastos económicos que se generan durante el proceso. Este punto es importante, ya que el juez puede ordenar, con fundamento en los Artículos 70, 71 y 72 de la Ley 472, que el Fondo para la Defensa de los Derechos e Intereses Colectivos, manejado por la Defensoría del Pueblo, sea el que asuma esta carga, cuando al accionante se le otorgue el amparo de pobreza que se solicita en el momento de presentar la demanda. ${ }^{25}$

El tema del amparo de pobreza se encuentra regulado por el Código de Procedimiento Civil, en los Artículos 160 a 167. Según el Artículo 160 del Código de Procedimiento Civil, el amparo de pobreza "es la medida que se otorga a quien esté en incapacidad de atender los gastos de un proceso", razón por la cual se lo libera de pagar cauciones, expensas, honorarios a auxiliares de la justicia, costas y cualquier otro gasto que se genere durante la actuación procesal. Al respecto, cabe mencionar que existen dos posiciones: la que asume la Corte Suprema de Justicia -haciendo una interpretación armónica entre los Artículos 160 y 161 del Código de Procedimiento Civil y el principio de buena fe-que indica que para solicitar amparo de pobreza basta enunciarse bajo gravedad de juramento y la posición del Consejo de Estado, según la cual para que proceda el amparo de pobreza debe demostrarse que se requiere dicho amparo.

d) Impulsión oficiosa: según el Artículo 5 de la Ley 472, la impulsión oficiosa del proceso es una obligación del juez, que le permitirá llegar a una sentencia de fondo. Por ello, el mismo artículo indica que, de no cumplir con dicha obli-

24 Corte Constitucional. Sentencia C-377 de 2002.

25 Artículo 70. Creacion y fuente de recursos. Créase el Fondo para la Defensa de los Derechos e Intereses Colectivos [...]. Artículo 71. Funciones del fondo. El Fondo tendrá las siguientes funciones: a) Evaluar las solicitudes de financiación que le sean presentadas y escoger aquellas que a su juicio sería conveniente respaldar económicamente, atendiendo a criterios como la magnitud y las características del daño, el interés social, la relevancia del bien jurídico amenazado o vulnerado y la situación económica de los miembros de la comunidad o del grupo; b) Financiar la presentación de las Acciones Populares o de Grupo, la consecución de pruebas y los demás gastos en que se pueda incurrir al adelantar el proceso; c) Efectuar los pagos correspondientes de acuerdo con las costas adjudicadas en contra de un demandante que haya recibido ayuda financiera del Fondo [...]. Artículo 72. Manejo del fondo. El manejo del Fondo para la Defensa de los Derechos e Intereses Colectivos, estará a cargo de la Defensoría del Pueblo. 
gación, el juez incurrirá en falta disciplinaria. Una de las formas de verificar la impulsión oficiosa, en el trámite de las acciones populares, es efectuando una revisión de las pruebas que decreta el juez de oficio, las cuales permiten aclarar "aspectos dudosos u oscuros"26 para luego emitir una sentencia de mérito o fondo.

De manera contradictoria El Consejo de Estado, en algunos de sus fallos, afirma que es el accionante quien debe asumir la carga de la prueba que permita demostrar los hechos que plantea en su demanda. Así, al no existir prueba de la vulneración o amenaza, las pretensiones no pueden prosperar. ${ }^{27}$

e) Prevalencia del derecho sustancial: medidas cautelares. La ley 472 de 1998 indica que, para prevenir un daño inminente o para hacer cesar el que se hubiere causado, antes de la notificación de la demanda y en cualquier estado del proceso el juez, ya sea de oficio o a petición de parte, podrá decretar las medidas cautelares que estime pertinentes, las cuales, de conformidad con el Artículo 25, son:

i. Ordenar la inmediata cesación de las actividades que puedan originar el daño, que lo hayan causado o lo sigan ocasionando;

ii. Ordenar que se ejecuten los actos necesarios, cuando la conducta potencialmente perjudicial o dañina sea consecuencia de la omisión del demandado;

iii. Obligar al demandado a prestar caución para garantizar el cumplimiento de cualquiera de las anteriores medidas previas;

iv. Ordenar con cargo al Fondo para la Defensa de los Derechos e Intereses Colectivos los estudios necesarios para establecer la naturaleza del daño y las medidas urgentes a tomar para mitigarlo.

Esta enunciación no es taxativa, ya que dependiendo de cada caso el juez ordenará las medidas que considere pertinentes. ${ }^{28}$ Estas medidas buscan proteger los derechos de manera previa e inmediata cuando, en algunos eventos, la

26 En la acción popular radicada con No. 17001-23-31-000-2003-01223-01 (AP), el actor expuso que la quebrada la Arboleda y un bosque primario por donde pasa ésta, ubicados en el Municipio de Manizales, venían siendo objeto de contaminación por aguas residuales no tratadas, lo cual afectaba el ecosistema de la región. El juez de primera instancia negó las pretensiones de la demanda porque no se demostró la contaminación, a pesar de que la parte demandada aceptó el vertimiento en quebradas afluentes. Por lo tanto, en la segunda instancia, la sección primera del Consejo de Estado mediante auto, de fecha 29 de septiembre de 2005, cuyo Consejero Ponente fue Gabriel Eduardo Mendoza Martelo, ordenó la práctica de pruebas de oficio a fin de "aclarar aspectos dudosos u oscuros de la controversia" y determinar si hubo o no contaminación.

27 Por ejemplo en las sentencias del Consejo de Estado: Sección Tercera. Radicación No. 52001 23-31-000-2004-02180-01 (AP) del 26 de Enero de 2006. Consejera Ponente: Sandra Mercedes Rivas Jiménez y Sección Tercera. Expediente No. AP-1471 del 29 de julio de 2004.

28 Consejo de Estado. Sala de lo Contenciosos Administrativo. Sección Tercera. Radicación No. 08001-23-31-000-2005-03595-01(AP). 18 de Julio de 2007. Consejero Ponente: Ramiro Saavedra Becerra. 
sentencia que así lo ordene puede no resultar eficaz. Esto ocurre principalmente en razón al tiempo, ya que de esperar hasta la sentencia que ponga fin a la acción pueden ocasionarse daños de manera inminente. Según el Consejo de Estado la finalidad de estas medidas es "evitar que el daño se concrete o que de estarse produciendo, no se prolongue por un término mayor" (Consejo de Estado).

Una vez verificados todos estos indicadores en el trámite de las acciones populares, puede decirse de una manera objetiva si la acción resultó o no eficaz para la protección de los derechos colectivos.

Como conclusión sostenemos que la eficacia emerge como un asunto fenomenológico del derecho. En Colombia, a partir de 1991, se configura como principio constitucional, de aplicación inmediata que, por un lado, guarda relación directa con el derecho fundamental del acceso a la justicia y que, por el otro, no sólo hace referencia al cumplimiento de las normas jurídicas por los ciudadanos, sino que también indica que los operadores jurídicos deben cumplir con ciertas actuaciones procesales que permiten la protección efectiva de los derechos colectivos.

Puede decirse también que la eficacia de la acción popular para proteger los derechos colectivos se mide de una manera objetiva con los indicadores que tanto la doctrina como la jurisprudencia constitucional han diseñado y que de manera armónica se consagran tanto en la Constitución como en la Ley 472 de 1998.

\section{Referencias}

Constitución Política de Colombia, 1991.

306 Código Civil, Ley 9 de 1980.

Decreto 2303 de 1989.

Ley 9 de 1989, Gaceta Constitucional, No. 22, p. 261.

Ley 472 de 1998.

Ley 1285 de 2009.

Bobbio, N. (1994). Teoría General del Derecho. Segunda Edición. Madrid: Temis.

Betegón Carrillo, J. et, al. (1997). Lecciones de teoría del derecho. Madrid; Macgraw-Hill.

Corte Constitucional. Auto 186 de 2006. 
Corte Constitucional. Sentencias: T-222 de 1992, T-378 de 1994, C-546 de 1992, C-542 de 1993, C-215 de 1999, C-1062 de 2000, C-365 de 2000, C-580 de 2002, C-377 de 2002, C-459 de 2004, C-569 de 2004, C-622 de 2007. 
